\title{
MAPPING HEALTH OPPORTUNITY: A CASE STUDY OF DORTMUND, GERMANY
}

\author{
Sushma Bajracharya
}

\author{
Lecturer, Department of Architecture, Khwopa Engineering College, Libali, Bhatapur
}

\begin{abstract}
Health being one of the most important aspects of life, people are much concerned about their health. Because people value their health, today cities are planned considering the health and environment for providing good quality of life. Many studies have shown different effects in health due to interaction with environment. As socioeconomic, environmental and cultural conditions may vary from place to place, people living in different areas in the cities can have different health outcomes. Also, people's perception of such neighbourhood conditions can vary which can influence their health. There can be different resources in and around the neighbourhood that provide opportunity for its people to perform different health-benefitting activities. Such physical features can be termed as health-related resources or in other words health opportunities.

This study was conducted in two different type of neighbourhoods in Dortmund, Nordstadt being deprived and Kreuzviertel being affluent. To know which locations people, consider as good or bad for their health, participants who agreed to take part in questionnaire survey were directly asked to point out the places they use and avoid for health-related activities. This study found out different types of health opportunities identified by respondents in Nordstadt and Kreuzviertel. Respondents from Nordstadt mentioned health opportunities inside and outside their neighbourhood whereas in Kreuzviertel health opportunities were pointed outside the neighbourhood. The information about people's perception on local neighbourhood can be taken as useful insights for planners and decision-makers to plan development programs. The research provides an opportunity to formulate policies that address main problems acting as barriers so that people can get maximum benefits from health opportunities. To find out detailed explanations for differences between actual and perceived environmental situation, more in-depth research is needed.
\end{abstract}

Keywords: Health related resources, Health opportunities, Perception, Neighbourhood characteristics.

\section{Introduction}

Health is one of the most important aspects of human life. Today, urban planning is done considering the health and environment aiming for good quality of life. The principles of Healthy Urban Planning developed by the World Health Organization were implemented in European cities which illustrates the integration of health in planning for the healthy environment (Barton and Grant, 2013).

\footnotetext{
*Corresponding author: Sushma Bajracharya

Department of Architecture, Khwopa Engineering College,

Libali-8 Bhaktapur, Nepal

Email: bajra.suss@gmail.com

(Received: 08 ${ }^{\text {th }}$ Jan 2019 Accepted: $7^{\text {th }}$ April 2019)
}

Likewise The Healthy Cities/Healthy Communities Movement concept has integrated health with urban planning by means of various approaches and programs that aim to improve the health and wellbeing of the community (Perlstadt, 2014).

Health equity is the central issue within the environmental health studies. "Health equity is absence of disparities in health between social groups who have different levels of underlying social advantage or disadvantage" (Braveman, 2003). Studies have revealed that the determinants of urban health equity like socioeconomic, cultural and environmental conditions, influence the health of the individuals and populations (WHO and UN Habitat, 
2010). Such factors define an area in the city and it can be said that where in a city one lives in and the way it is governed can determine if or not one benefits (WHO and UN Habitat, 2010). This means that people living in deprived and affluent areas in the city can have different health outcomes.

Spotting out the resources in and around the neighbourhood by directly asking the residents of that area can be one of the way to understand about what features of the neighbourhood people consider good or bad for their health. Such resources can be any physical feature in neighbourhood that give opportunity for people to perform activities that can be beneficial to their health. The health-related resources as such are the health opportunities. Health opportunities can be categorised into four types based on the literature. These different type of resources considered as health opportunities in this study are:

Resources related to health care such as hospitals, general practitioners, pharmacies, clinics, health care facilities etc.

Resources related to physical activity such as recreational and leisure centres, public open spaces, parks, sports centres, health clubs, fitness centres, cycling trial, walking or jogging trail etc.

Resources related to food such as supermarkets, grocery shop, fast food outlets, alcohol outlets, restaurants etc.

Resources related to social connections such as cafes, coffee shops, community centres etc., which are used as venues for informal meeting, discussion, social gatherings and social interactions.

Health-related resources can play a significant role in making lives of people healthy. However, the perception of the people about such resources in their neighbourhood have not been recognized and different characteristics linked with such healthrelated resources have not been identified. Such perceived neighbourhood characteristics can be supporting or limiting the use of health-related resources. Based on literature, the neighbourhood characteristics that can play role in achieving good health can be:
Social characteristics such as crime, vandalism, drug dealing, litter and rubbish (cleanliness), safety (may be due to traffic, street light), access to potential health opportunities, social cohesion etc.

Environmental characteristics such as air pollution, noise pollution, smell or odour. Air quality is deteriorated because of one or more air pollutants such as nitrogen dioxides (NO2), sulphur dioxides (SO2), fine particulate matter (PM), ground-level ozone (O3), etc. Particulate matter (PM) is mixture of aerosol particles. PM10 refers to particles with a diameter of 10 micrometers or less. PM is emitted from natural sources as sea salt, volcanic ash and naturally suspended dust as well as from anthropogenic sources such as fuel combustion for vehicles, vehicle tyre and brake, road wear, domestic heating etc. NO2 and PM10 are both measured in micrograms per cubic meter $(\mu \mathrm{g} / \mathrm{m} 3)$. Likewise, noise is also considered as an environmental issue that can also have adverse effect on health such as hearing impairment, cardiovascular and physiological effects, sleep disturbance, etc (WHO, 2011). The various sources of noise include road traffic, railways, aircrafts, industries etc. (EEA, 2014).

There can be numerous health opportunities in the neighbourhood which are relevant for better health of its people. However, everyone in the neighbourhood might not make use of all of those opportunities. There can be many reasons behind this. Some might even be unaware of such opportunities existing in their neighbourhood whereas others might not use those opportunities because of their socioeconomic condition. Use of the health opportunities depends on many factors such as, the quality of the services they provide, accessibility, cost, etc. Also, as different people have different opinions and views about same thing, people can perceive same opportunity in different ways. The characteristics of the place where the resources are located can also influence people's perception. Because of individual personal characteristics and characteristics of place, people might not be using the health opportunities. If the factors acting as barrier to use the health opportunities can be known, necessary measures required to remedy such impediments can be taken. Therefore, through the use of people's perception, not only various perceived resources can be identified but 
also perceived neighbourhood characteristics related to such perceived resources can also be understood.

Understanding the geographic distribution of such health opportunities could inform policymakers about the problems and dissatisfactions of the public regarding different neighbourhood factors where the health opportunities are located. This in turn can assist in identifying necessary measures required to remedy the barriers to the health opportunity. The inclusion of people's perception about the health opportunities can bring decision-makers and public together to better inform further interventions. Health opportunity maps can show the linkages between people and the areas of opportunity related to health.

\section{Research Objectives and Conceptual Framework}

The main objective of this research was to map health opportunities as indicated by people in two contrasting neighbourhoods. The main objective was fulfilled by identifying the health-related local resources in deprived and affluent neighbourhoods, identifying the perception of people on neighbourhood characteristics for used and avoided health-related resources and checking the match or mismatch between the objective and subjective neighbourhood characteristics of the locations of those resources.

Perception of health-related resources was distinguished into used resources and avoided or not used resources. The personal characteristics such as gender, age, migrant background, education level and employment were considered for this research. The research helped to map different health opportunities as mentioned by people of different gender, age groups, education, migration background and occupation. Also, the research found out which dimensions of their neighbourhood people perceive particularly relevant for using the health opportunities and which dimensions they perceive as barrier for using those health opportunities. The match or mismatch between actual and perceived neighbourhood characteristics were further checked to assess to what extent the actual and perceived neighbourhood characteristics coincide. Based on the result, planning interventions could be suggested intended to improve neighbourhood characteristics. Fig. 1 shows the flow diagram of framework.

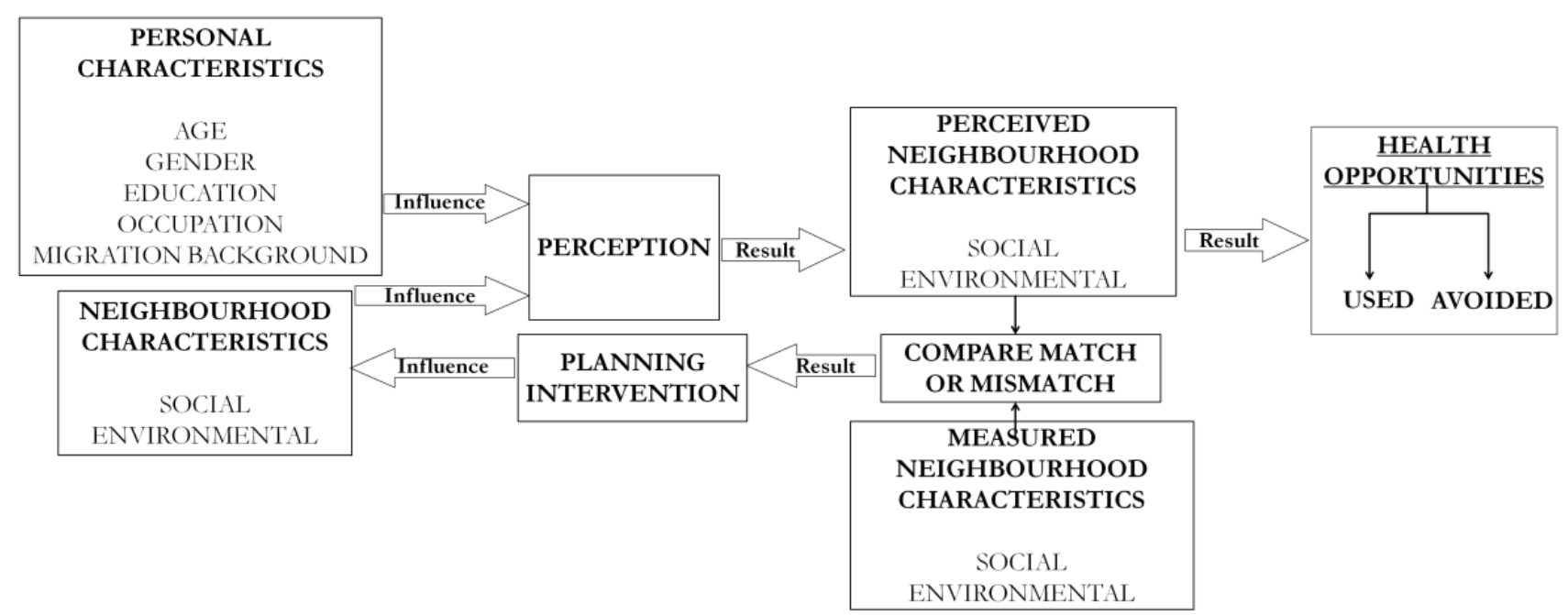

Fig. 1. Conceptual Framework 


\section{Case Study Area and Selection Criteria}

The case study area was Dortmund, Germany. It is the largest city in Ruhr area and eighth largest city in Germany with nearly 600,000 inhabitants. The city is divided into 12 city districts, 62 statistical districts and 170 statistical sub districts. The city of Dortmund is in the centre of Europe with excellent infrastructure and green parks in almost half of its urban area. Dortmund is the heart of Westphalia and is surrounded by eleven neighbours. Dortmund was industrial city with breweries, coal mining and iron extraction industries in the early 19th century. The population started to grow along with different traditional structures. The migrant workers from other countries such as Turkey, Italy, and Spain came to Dortmund to work in mines. As a result, there was a necessity of accommodation for growing migrant population.

Presently, the city has research institutes, private universities and information technology companies ("City History - Home," n.d.; "Links - History Town portrait - life in Dortmund - city portal dortmund.de," n.d.). There are deprived areas with mixed land use (residential area near industry and commercial) towards the north of Dortmund. Such areas have higher migrant population compared to other districts. The distribution of green space is also low in such areas (Flacke and Kockler, 2015).
The study area selected towards the north of the city is Nordstadt being worst off and the second study area selected towards the west of the city is Kreuzviertel being better off area (Fig. 2). Both study areas are urban areas near by the city centre of Dortmund. Nordstadt is the inner-city area resided by mostly migrant population. The second study area includes residents that are more affluent. Both study areas were selected based on the suggestions by experts from the Jufo Salus research network.

The secondary data shows that northern part of the city is resided by high population than in the southern part and also, the share of population with migration background is higher in the northern areas of the city in comparison to the southern parts of the city. Fig. 3 shows that population density is higher in Nordstadt compared to Kreuzviertel. Fig. 4 shows availability of green areas in and around two areas. The green areas have been classified as public, private and urban garden. The public green areas include public parks, gardens and other green areas accessible to public such as zoo, cemetery. Private Green areas include private gardens in residential areas. Urban garden includes garden plots which people can own. The map shows green areas are available in the immediate surroundings of Kreuzviertel and within the neighbourhood. But, green areas can be seen bit far from Nordstadt and very few green areas can be noticed within the neighbourhood. This shows unequal availability of green areas in two areas.

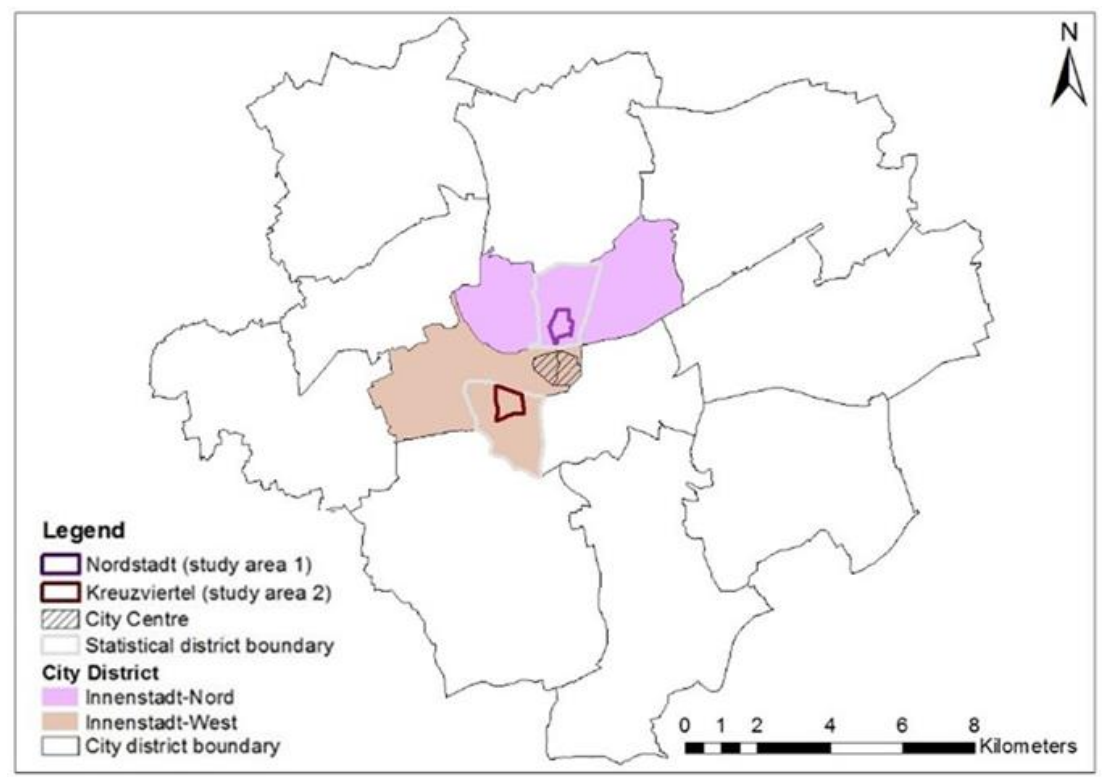

Fig. 2. Map of Dortmund showing sampling frames (Nordstadt and Kreuzviertel) 


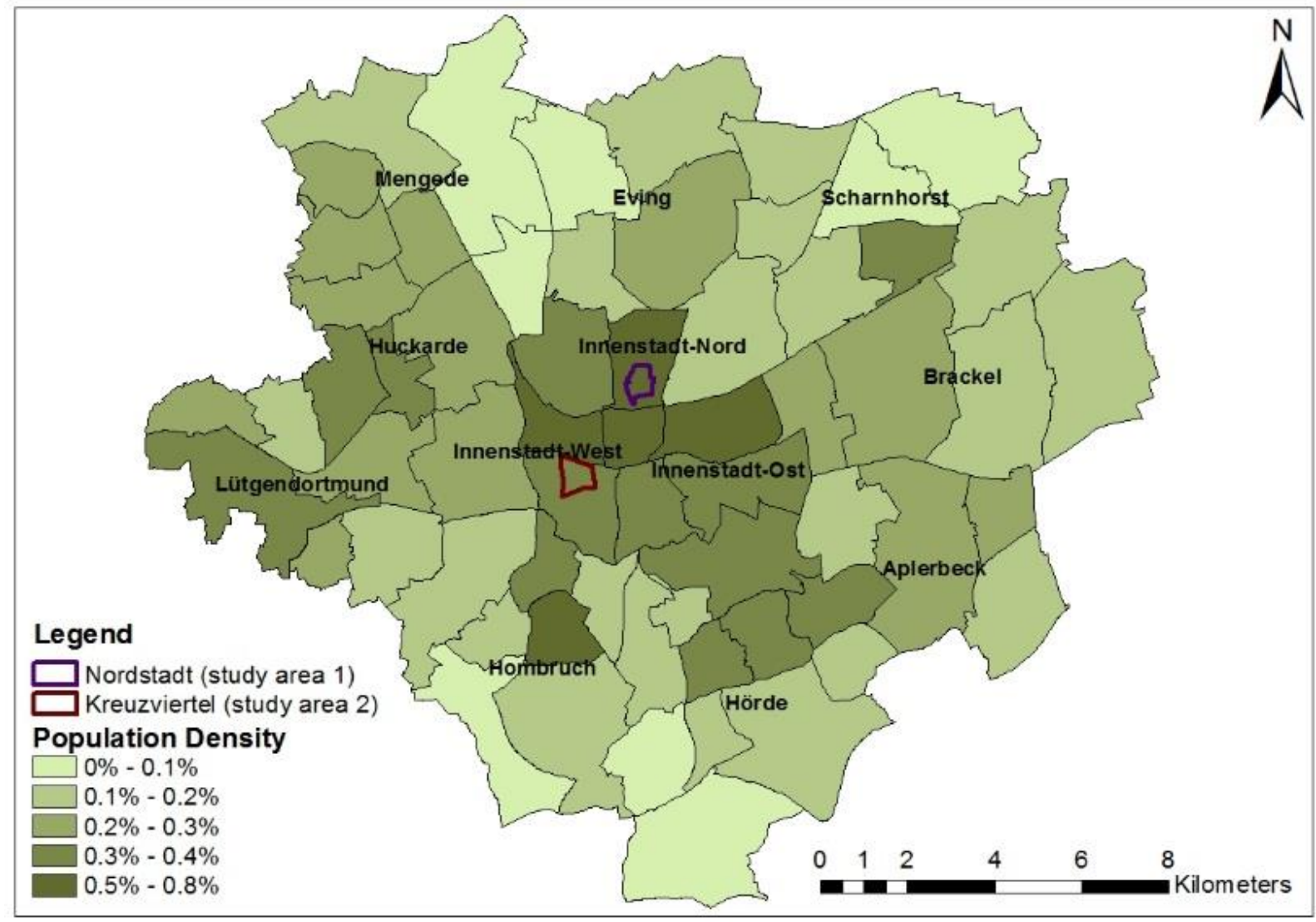

Fig. 3. Map showing population density in Dortmund

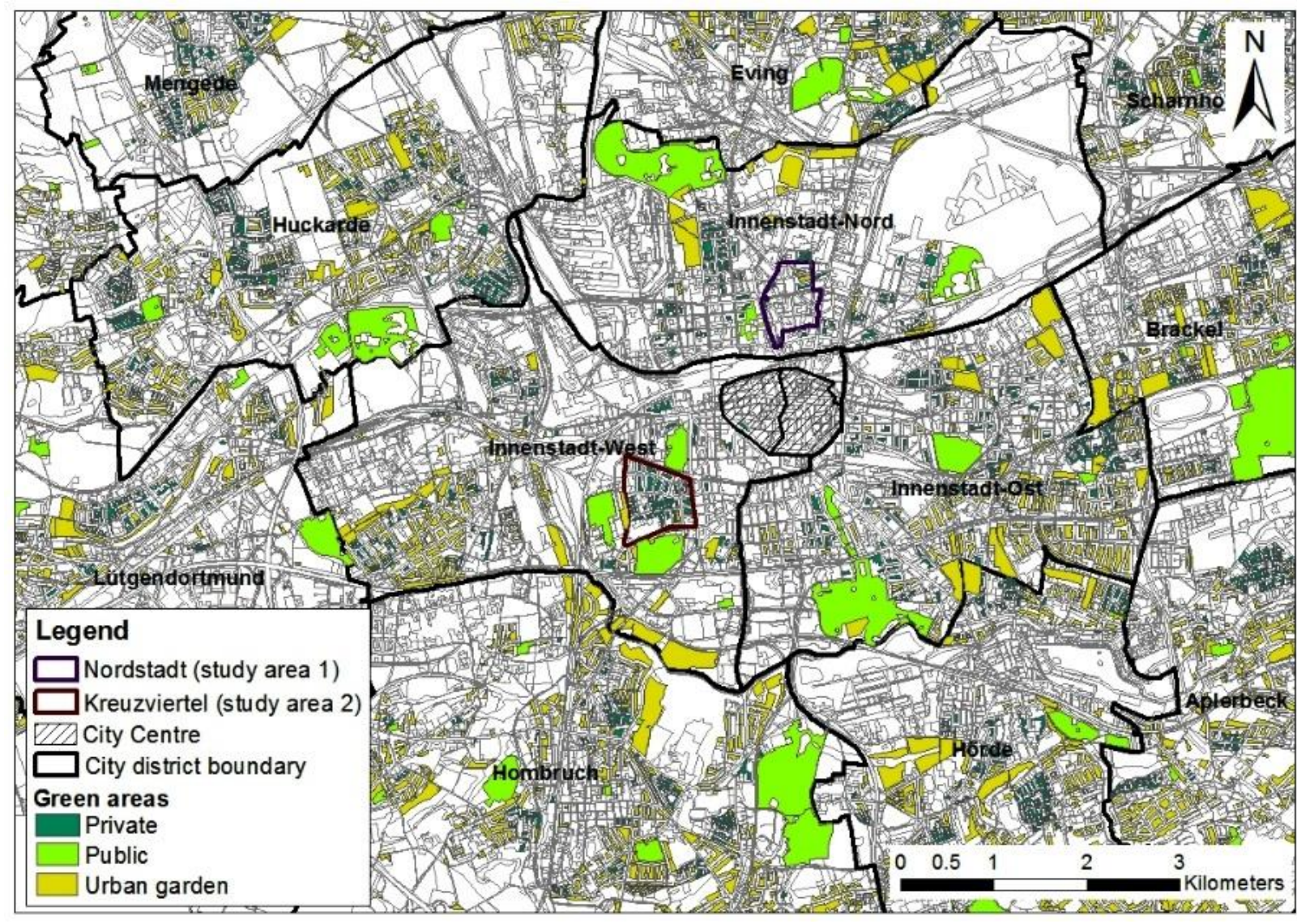

Fig. 4. Map showing green areas in and around the study areas 


\section{Research Design and Methodology}

First, theoretical knowledge on health opportunities, perceptions of people on neighbourhood characteristics, participatory methods to capture perception, method to analyse the actual and perceived neighbourhood characteristics were obtained. Next, primary data was collected using questionnaire. Pilot surveys were conducted after which modifications were made to questionnaire. For the research, quota sampling was chosen as the sampling strategy to select the respondents based on characteristics like gender, age, migrant, education and occupation.

For data collection, closed-questionnaire was used as the research instrument as questionnaire is an important instrument of research and one of the tools for data collection (Oppenheim, 1992, p. 100). Interviews were conducted with people in two study areas. Structured questions were used with options and evaluation scale. Paper maps were used to point out different locations as indicated by respondents. The data collected from interview was entered into GIS database and analysed using descriptive statistical analysis method. The perception of people on health opportunities and reasons in terms of social and environmental characteristics of the place were analysed. The results and findings were discussed and concluded. The flowchart for research design and methodology is shown in Fig. 5.

\section{Results and Discussions}

\subsection{Health Opportunities in Nordstadt and Kreuzviertel}

In both the study areas, respondents had mentioned about parks, public open spaces and neighbourhood streets for different activities. Studies have shown that people use outdoor and freely available facilities most frequently for physical activity than gyms, exercise centres and health clubs (C. Lee and Moudon, 2004; Giles-Corti and Donovan, 2002). Most of the respondents from Nordstadt and Kreuzviertel pointed parks as the used health opportunities especially for physical activity and social relationship. This result was no different from the findings of research (Chappell and Funk, 2004) that mentioned use of green areas such as parks for socialization and physical activities. Social connection seemed to be more important for respondents in Nordstadt as they had mentioned use of different locations where they could perform health related activities in combination with meeting friends. They had pointed out parks, market areas, food shops, restaurants and fitness centres where they meet friends apart from other activities. It is mentioned somewhere (Maas, van Dillen, Verheij, and Groenewegen, 2009) that for people with low income and low education, like in Nordstadt, social contacts are important and for this they use green space in their living environment. Most of the respondents avoided footpaths or routes. Regarding the street ways or footpaths and the route, qualities like perceived safety, convenience, visual quality of the roadway and roadside environments, streetcrossing conditions can play role that influence one's decision to use or not to use that route for different activities like walking (Lee and Moudon, 2004).

When comparing spatial distribution of mapped locations, respondents from Nordstadt mentioned resources which were within their neighbourhood and nearby locations as health opportunities (Fig.6). But in case of Kreuzviertel, respondents pointed out locations distant from their place of stay as health opportunities (Fig.7). This can be supported by research (Cohen et al., 2003) which mentions local neighbourhood resources are more important for low socioeconomic people than high socioeconomic people as rich people have ability to travel to distant places for beneficial health.

Perception of respondents from Nordstadt, for different locations identified as health opportunities (used and avoided combined) are shown in maps from Fig. 8 to Fig. 14 whereas maps from Fig. 15 to Fig. 21 represent perception of respondents from Kreuzviertel. The maps show respondents' perception for different neighbourhood characteristics. The positive and negative perception about neighbourhood characteristics for used health opportunities are represented by 'Used_good' and 'Used_bad' respectively. Similarly, the positive and negative perception about neighbourhood characteristics for avoided health opportunities (HO) are represented by 'Avoided_good' and 'Avoided_bad' respectively. 


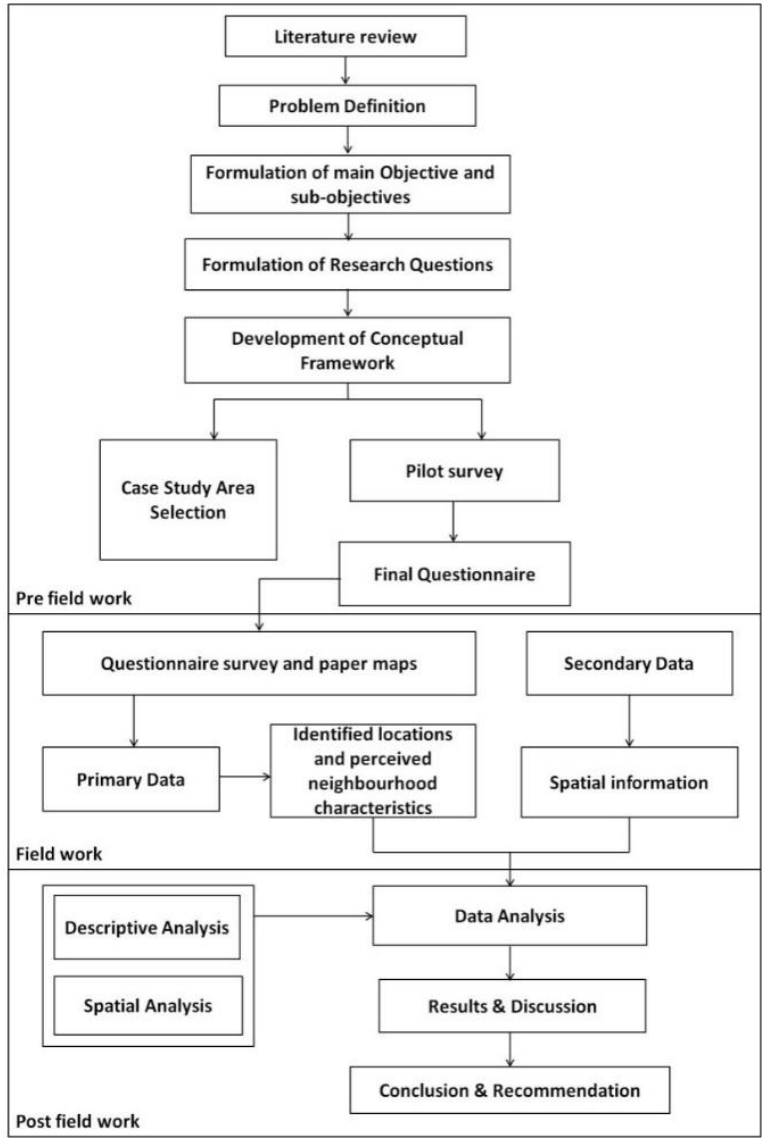

Fig. 5. Research Design and Methodology

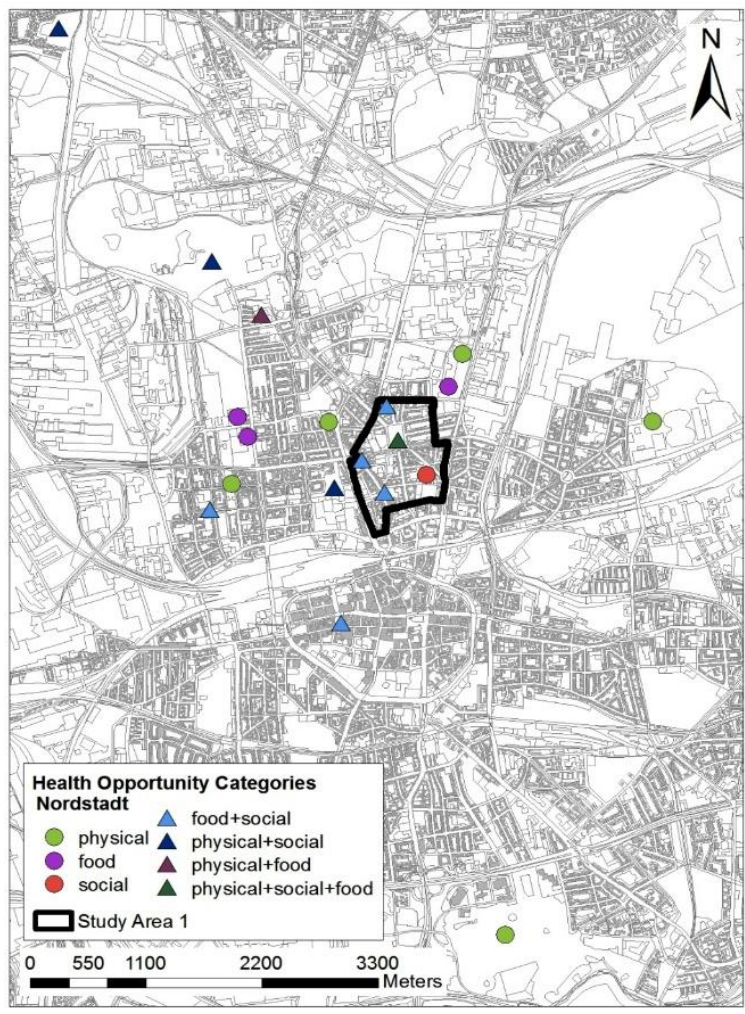

Fig. 6. Map showing categorization of used health opportunities in Nordstadt

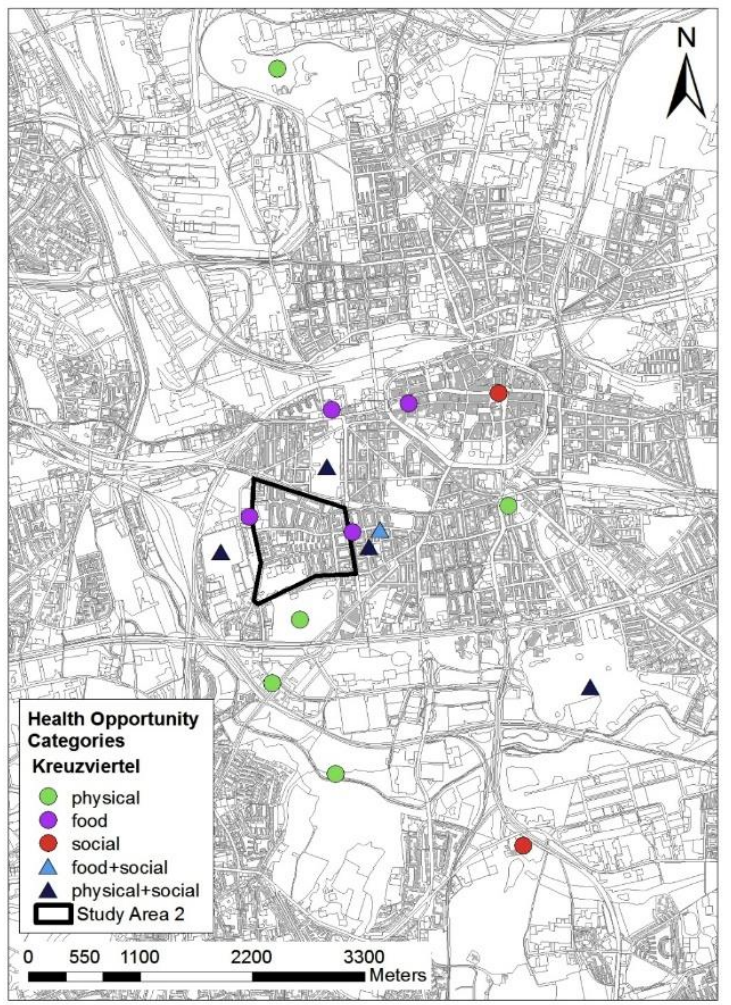

Fig. 7. Map showing categorization of used health opportunities Kreuzviertel

This result calls for further study to find reasons behind positive and negative perception so that neighbourhood characteristics can be improved and people can benefit by using the resources in their neighbourhood.

\subsection{Personal Characteristics Based Perception of Neighbourhood Characteristics for Health Opportunities in Nordstadt and Kreuzviertel}

Respondents from Nordstadt were mostly male, young, with low education level, migrants and unemployed whereas it was just opposite in case of Kreuzviertel. People were highly educated, nonmigrants and mostly retired in Kreuzviertel. The variation in the perception can be explained based on this compositional characteristic.

Table 1 and Table 2 below show neighbourhood characteristics that participants mentioned most for using and avoiding health opportunities with personal characteristics that were found to perceive these most mentioned neighbourhood characteristics in Nordstadt and Kreuzviertel. 


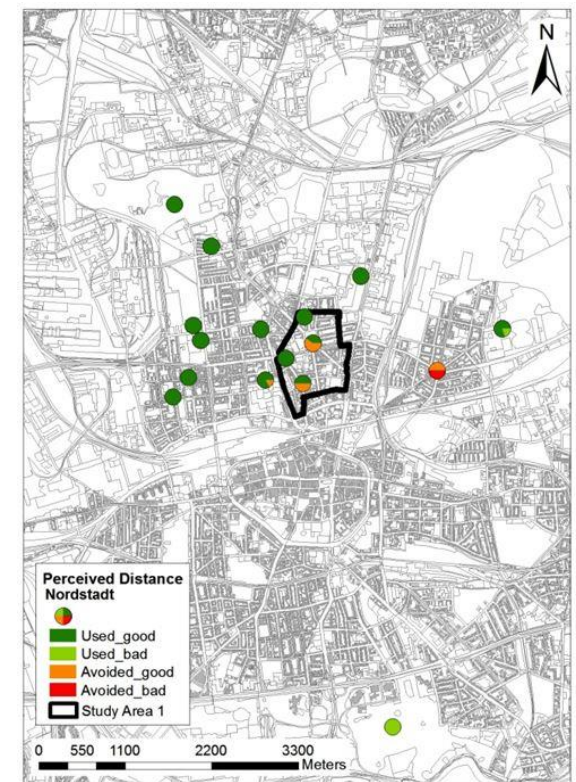

Fig. 8. Perception of distance in $\mathrm{HO}$ in Nordstadt

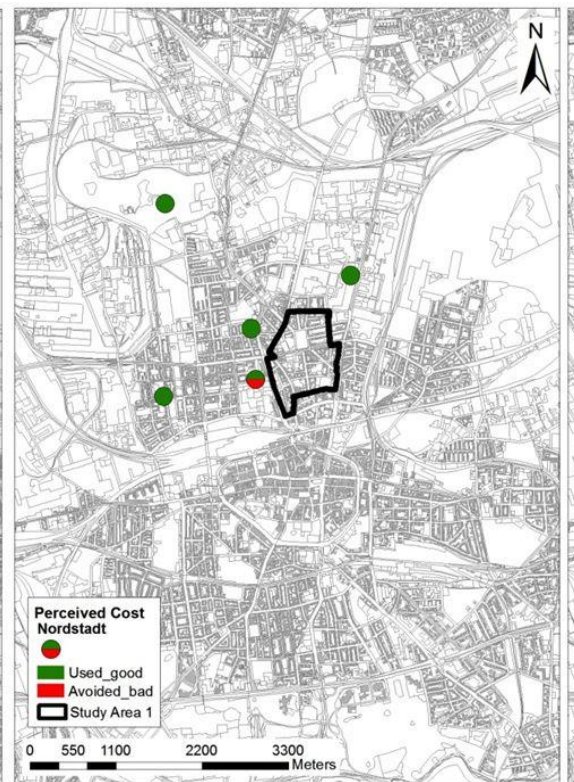

Fig. 9. Perception of cost of resources in $\mathrm{HO}$ in Nordstadt

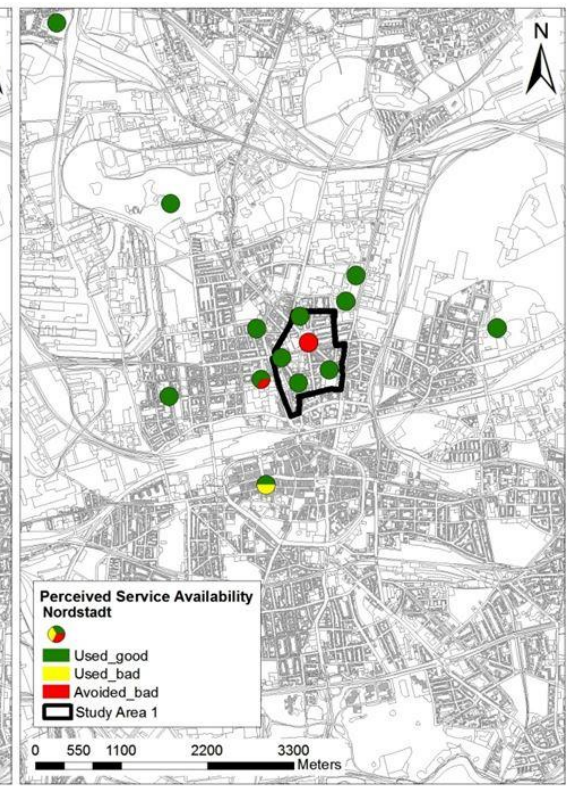

Fig. 10. Perception of service availability in $\mathrm{HO}$ in Nordstadt

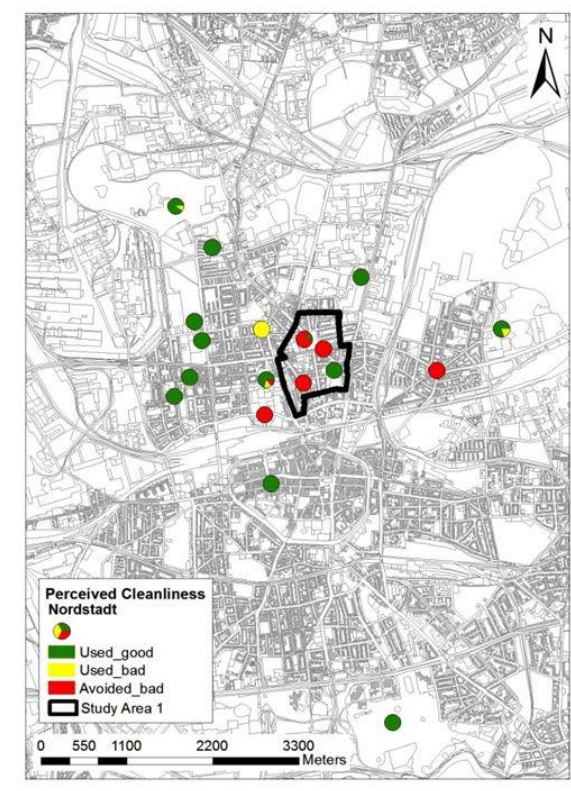

Fig. 11. Perception of cleanliness in HO in Nordstadt

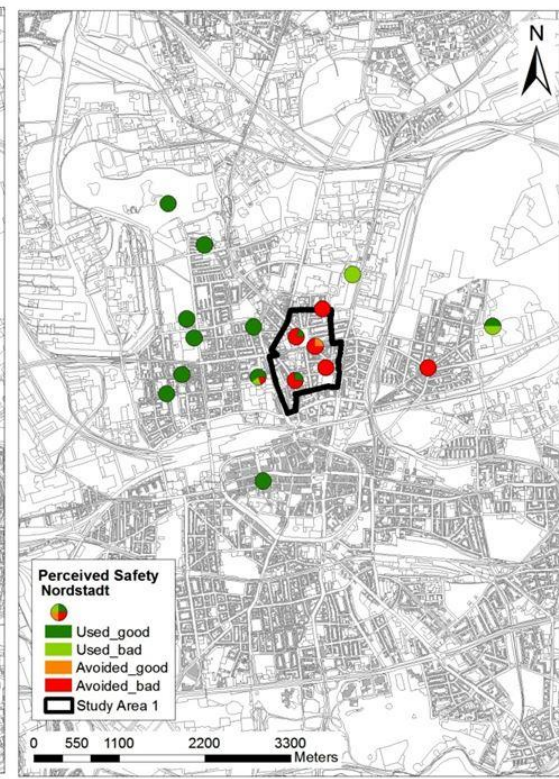

Fig. 12. Perception of safety in HO in Nordstadt

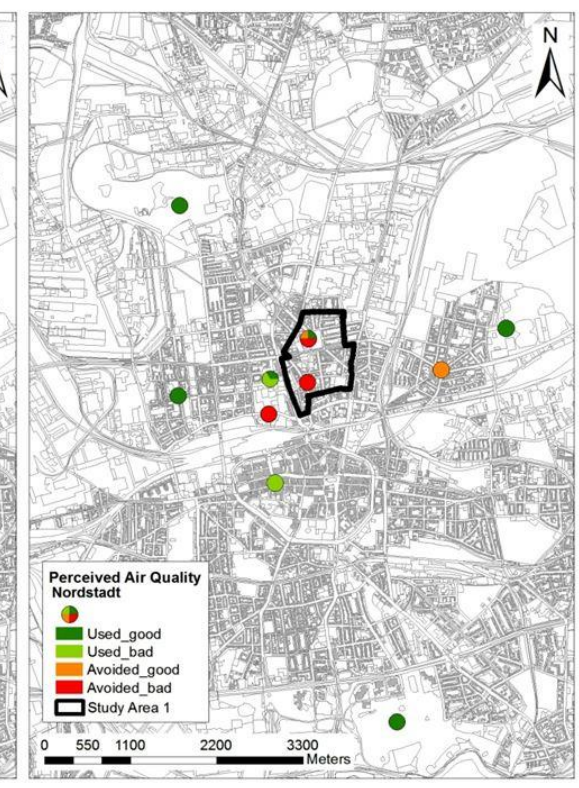

Fig. 13. Perception of air quality in $\mathrm{HO}$ in Nordstadt

Table 1: Personal characteristics based perception of neighbourhood characteristics in used and avoided health opportunities in Nordstadt

\begin{tabular}{|c|c|c|c|}
\hline \multicolumn{2}{|c|}{ Used Health Opportunities in Nordstadt } & \multicolumn{2}{c|}{$\begin{array}{c}\text { Avoided Health Opportunities in } \\
\text { Nordstadt }\end{array}$} \\
\hline Distance to place & Cleanliness in place & Safety in place & Noise in place \\
\hline Male & Male and female & Female & Male \\
\hline Young age & Old age & Young Age & Young age \\
\hline $\begin{array}{c}\text { with migration } \\
\text { background }\end{array}$ & $\begin{array}{c}\text { with migration } \\
\text { background }\end{array}$ & $\begin{array}{c}\text { without migration } \\
\text { background }\end{array}$ & $\begin{array}{c}\text { with migration } \\
\text { background }\end{array}$ \\
\hline low and more educated & low educated & low educated & more educated \\
\hline employed & employed & unemployed & unemployed \\
\hline
\end{tabular}




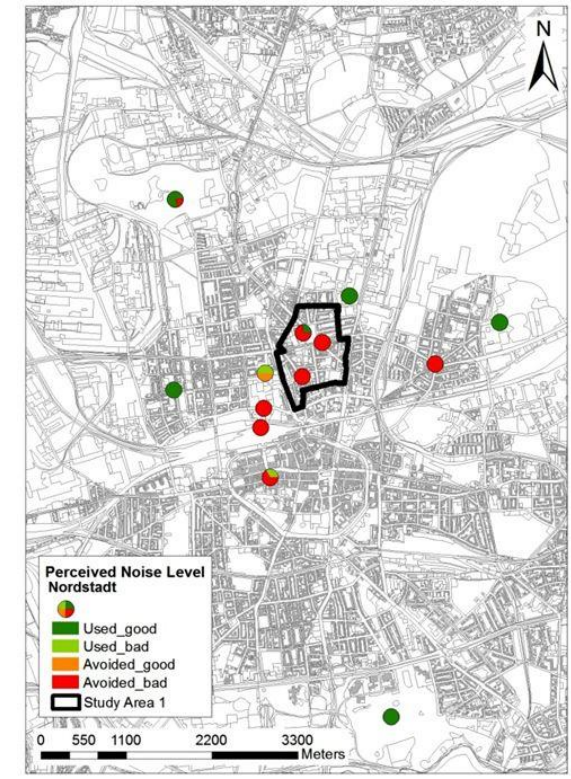

Fig. 14. Perception of noise level in $\mathrm{HO}$ in Nordstadt

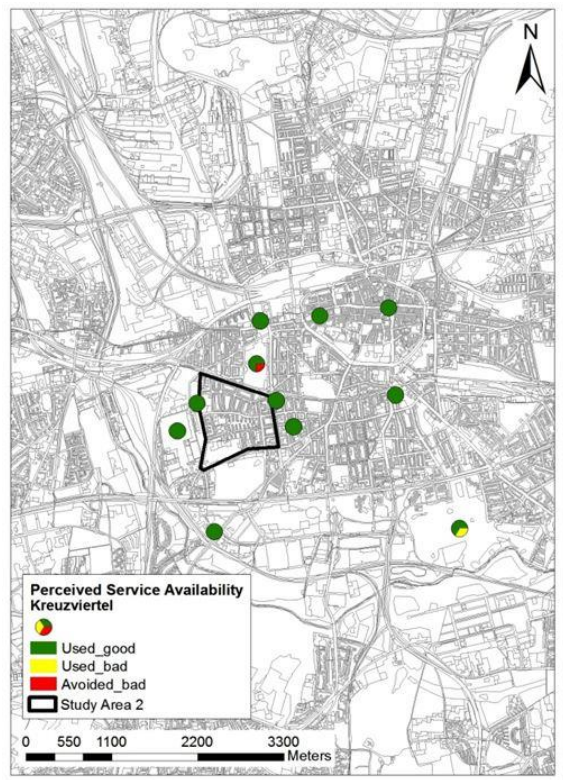

Fig. 17. Perception of service availability in $\mathrm{HO}$ in Kreuzviertel

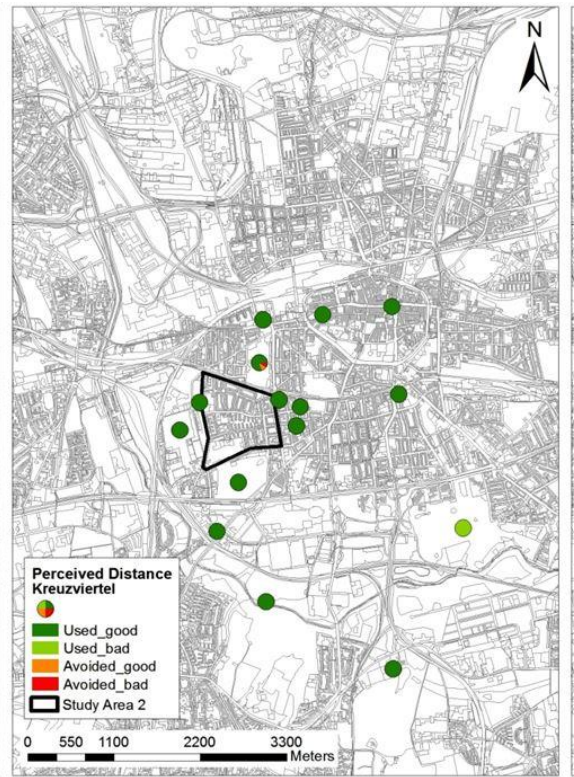

Fig. 15. Perception of distance in $\mathrm{HO}$ in Kreuzviertel

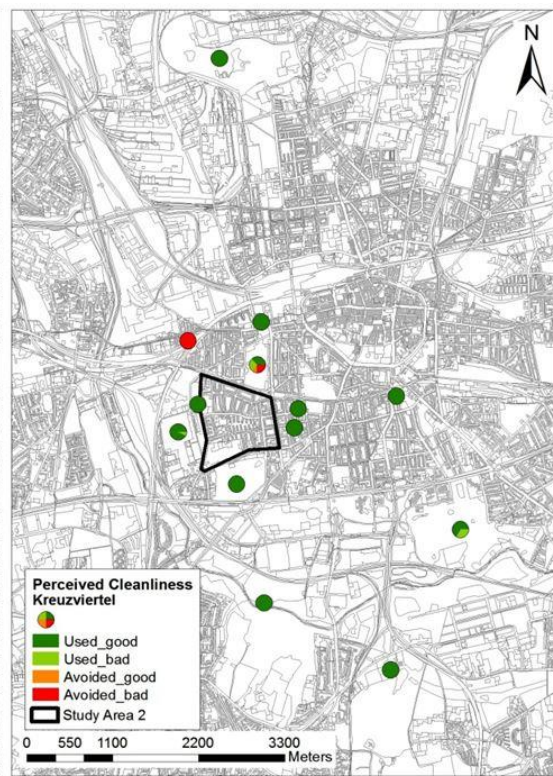

Fig. 18. Perception of cleanliness in $\mathrm{HO}$ in Kreuzviertel

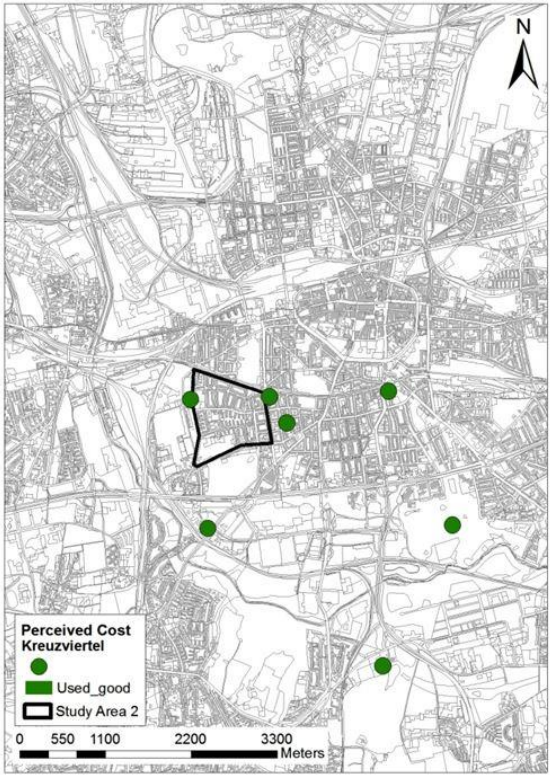

Fig. 16. Perception of cost of resources in $\mathrm{HO}$ in Kreuzviertel

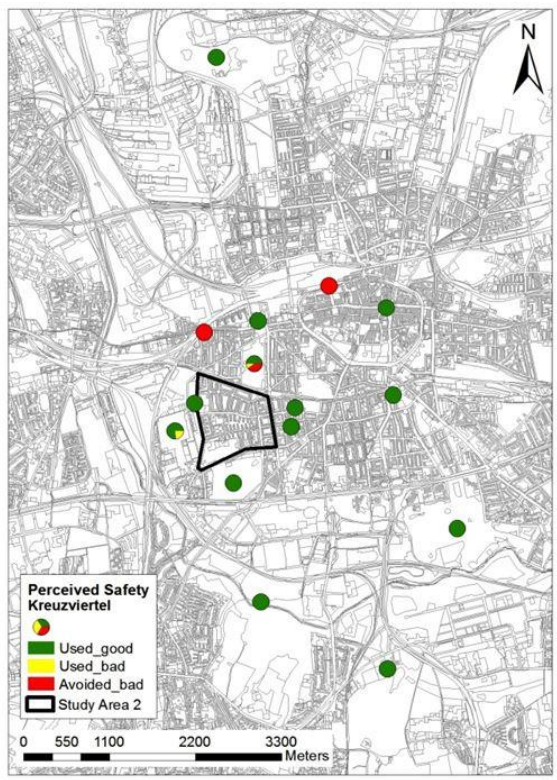

Fig. 19. Perception of safety in $\mathrm{HO}$ in Kreuzviertel

Table 2: Personal characteristics based perception of neighbourhood characteristics in used and avoided health opportunities in Kreuzviertel

\begin{tabular}{|c|c|c|c|}
\hline \multicolumn{2}{|c|}{ Used Health Opportunities in Kreuzviertel } & \multicolumn{2}{c|}{ Avoided Health Opportunities in Kreuzviertel } \\
\hline Distance to place & Cleanliness in place & Safety in place & Noise in place \\
\hline Male & Male & Female & Male \\
\hline Young age & Old age & Young Age & Young age \\
\hline $\begin{array}{c}\text { with migration } \\
\text { background }\end{array}$ & $\begin{array}{c}\text { with migration } \\
\text { background }\end{array}$ & $\begin{array}{c}\text { without migration } \\
\text { background }\end{array}$ & $\begin{array}{c}\text { without migration } \\
\text { background }\end{array}$ \\
\hline low and more educated & low educated & low and more educated & low and more educated \\
\hline employed & unemployed & employed & unemployed \\
\hline
\end{tabular}




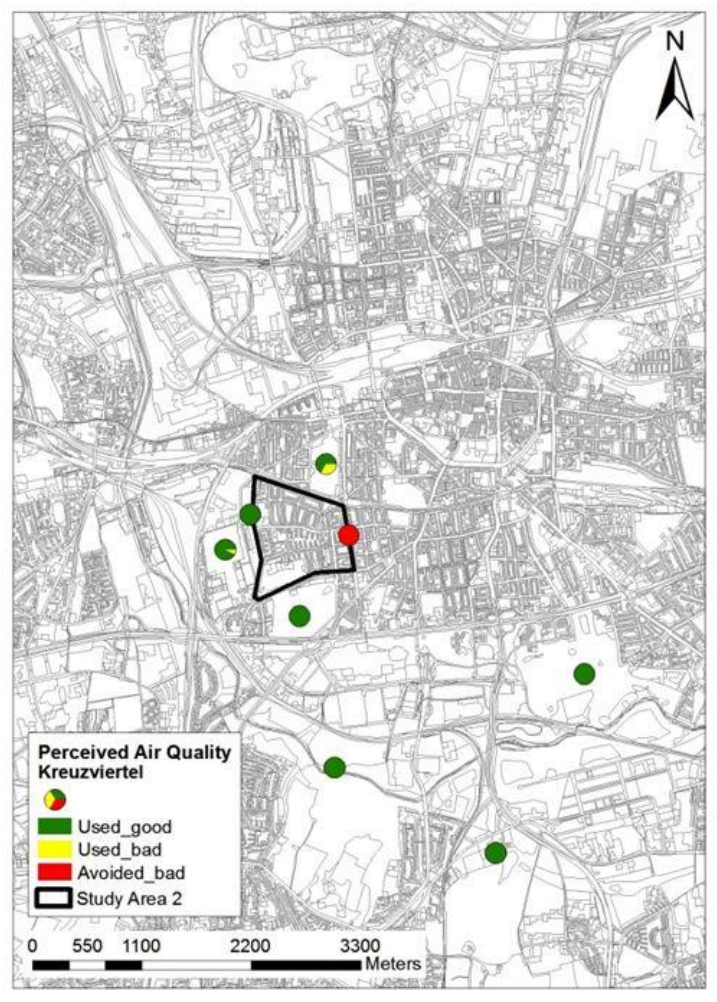

Fig. 20 Perception of air quality in HO in Kreuzviertel

From Table 1 and Table 2, gender-based perception shows that women perceived social characteristics (safety) and men perceived environmental quality (noise) in both deprived and affluent areas. Agebased perception shows younger respondents were concerned with safety and noise in both areas. Respondents without migration background perceived safety in both areas whereas for noise, those with migration background were sensitive in deprived area (Nordstadt) and non-migrants were found sensitive to noise in affluent area (Kreuzviertel). Low educated participants reported safety and more educated were concerned about noise level in Nordstadt. In Kreuzviertel respondents regardless of education level, mentioned safety and noise as important neighbourhood characteristics. Unemployed respondents from both areas perceived noise. Employed people reported about safety in Kreuzviertel but unemployed were concerned in Nordstadt. Men, younger respondents, employed, migrants, regardless of education level perceived distance for using health opportunities in both areas. Older, migrants, low educated, employed, both men and women in Nordstadt perceived cleanliness. In Kreuzviertel, older, migrants, low educated,

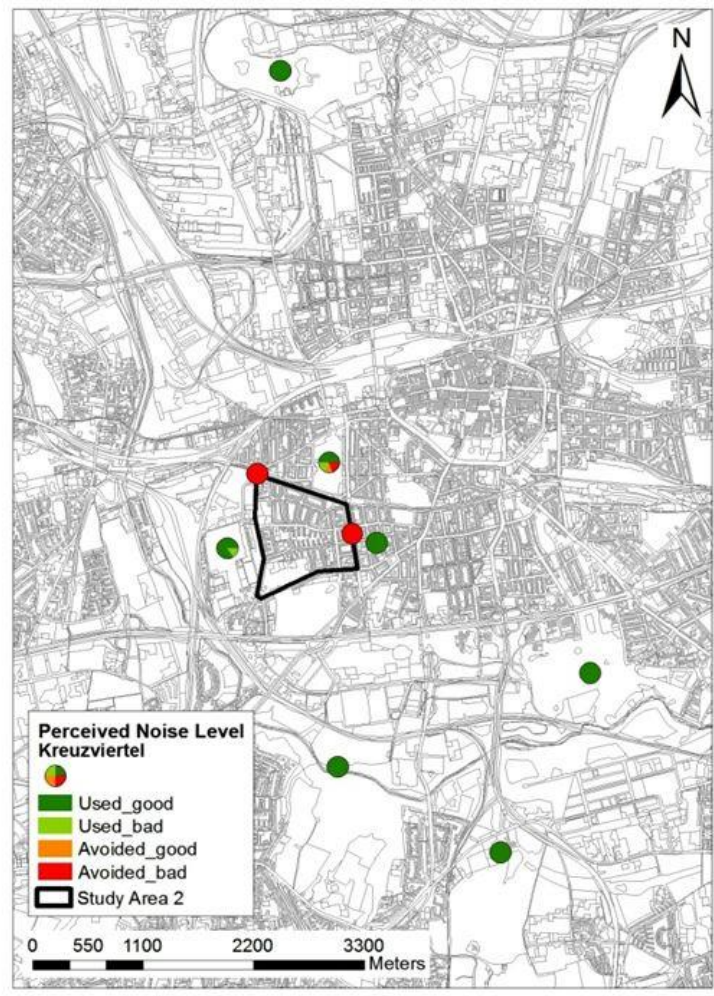

Fig. 21. Perception of noise level in HO in Kreuzviertel

unemployed and men perceived cleanliness for using health opportunities.

Researchers have shown that perceptions of people vary by education, nativity, family structure and gender (Roosa, White, Zeiders, and Tein, 2009). Immigrants are more sensitive towards safety, mainly women. Also, less educated men and women perceive danger more than those more educated. However, in Nordstadt where migrant population is higher, respondents without migration background were sensitive towards safety. Perhaps, this is because, as mentioned in some research that, for people living in neighbourhood with socioeconomic or ethnic mix different from their own have fewer social relationships locally which can create distrust and feeling of unsafety (Parkes, Kearns, and Atkinson, 2002). The study also mentioned that people who are unemployed and with low income who cannot easily protect themselves from neighbourhood problems, have more dissatisfaction with neighbourhood problem. This can be the case for respondents with migration background from Nordstadt who reported dissatisfaction with noise level. The dissatisfaction with noise for the respondents from Kreuzviertel can be supported by 
research (Kruize, 2007, p. 212) which mentions that those living in higher income area or more educated people are concerned with absence of noise in neighbourhood in comparison to those living in low income area or low educational level.

\subsection{Comparative Analysis of Results from Deprived Area (Nordstadt) and Affluent Area (Kreuzviertel)}

Comparison between the perceptions of respondents from two areas was done first for used health opportunities and second for avoided health opportunities. This variation in perception of neighbourhood characteristics between respondents from two study areas has been illustrated in Fig. 22 where one radar chart illustrates the difference in perception of neighbourhood characteristics for used health opportunities and the other illustrating difference for avoided health opportunities.

In case of used health opportunities, respondents from both areas- Nordstadt and Kreuzviertel, perceived distance and cleanliness most important followed by safety in case of Nordstadt and by environmental characteristics (air quality and noise) in case of Kreuzviertel. This means safety is matter of concern for those from Nordstadt whereas environmental quality is more important for those from Kreuzviertel. Comparatively, respondents from Nordstadt were more concerned about both distance and cleanliness than those from Kreuzviertel. However, perception of safety was equal. The chart shows that availability of services and cost were considered more by participants from Nordstadt.

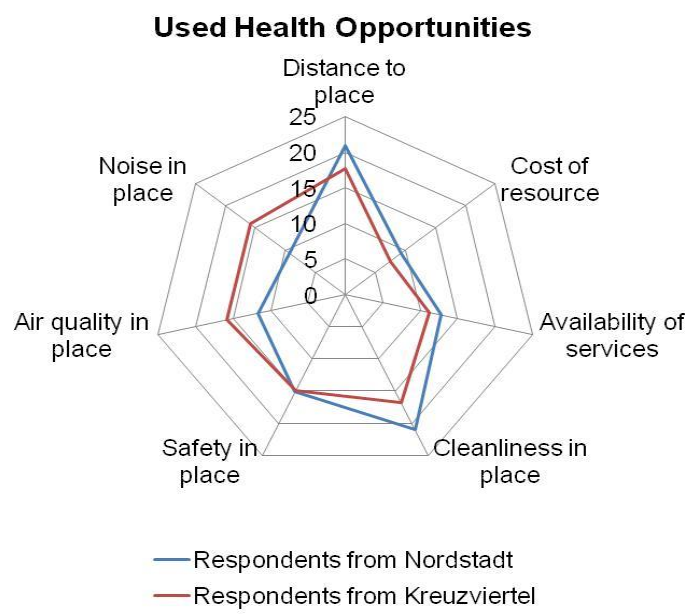

Regarding, avoided health opportunities, safety was the main concern in both areas. Noise was perceived after safety in Kreuzviertel whereas for respondents in Nordstadt, cleanliness was important than noise after safety. This comparison between responses shows that distance and cleanliness were important for using health opportunities for the participants from both areas. Participants from Kreuzviertel perceived environmental characteristics more while participants from Nordstadt perceived unsafety more than noise and air quality and avoided health opportunities.

\subsection{Comparison of Match or Mismatch between Actual and Perceived Environmental Quality}

The respondents from both areas reported air quality and noise to be the reason for using and avoiding different locations as health opportunities, so these qualities were assessed. Air pollutants such as NO2 and PM10 cause air pollution. Such pollutants are harmful to health. Similarly, noise from different sources such as road traffic, railways and industries can also have adverse health effects. For Dortmund, threshold value for the annual average concentration of both $\mathrm{NO} 2$ and PM10 are set as $40 \mu \mathrm{g} / \mathrm{m} 3$ each (SimuPLAN, 2013, p. 11). The threshold value for total noise from various sources is considered $55 \mathrm{~dB}$ (decibel) in Dortmund (SimuPLAN, 2013, p. 11).The total noise level not exceeding $55 \mathrm{~dB}$ is considered as good whereas annual average concentration of PM10 and $\mathrm{NO} 2$, each not exceeding $40 \mu \mathrm{g} / \mathrm{m} 3$ is considered good. The total noise level combines the noise from street, train, tram and industries.

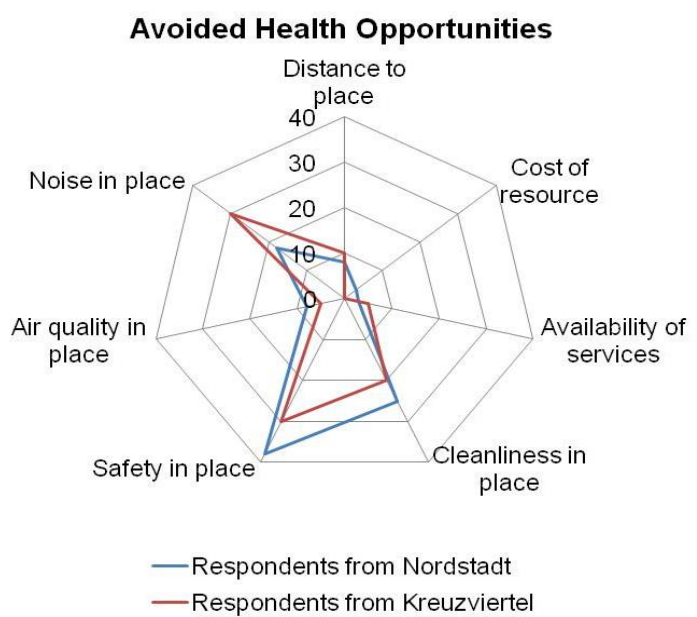

Fig. 22. Reasons for using and avoiding health opportunities in Nordstadt and Kreuzviertel 
The differences between actual and perceived environmental quality were assessed only for the locations where respondents considered noise and air quality as the reasons for using and avoiding those locations.

In both areas, there was a match situation $\mathrm{AbPb}$ (Actual bad Perceived bad) which needed urgent attention. In Nordstadt more locations were unsuitable to be used as health opportunity because of high noise level. More locations in Nordstadt were reported with negative perception of noise and air quality despite of good measured environmental quality in comparison to Kreuzviertel. In Nordstadt, some locations were avoided despite of good environmental quality. More locations in Kreuzviertel were reported with satisfaction with noise level while the actual value is bad.

It has been mentioned in other research that people residing in higher income areas perceive their neighbourhood positively and they have capacity and possibilities to influence the decision-making regarding their neighbourhood (Kruize, 2007). Perhaps, this can be one of the reasons for less locations with mismatch situation $\mathrm{AgPb}$ (Actual good Perceived bad) reported by respondents in Kreuzviertel than in Nordstadt.

This study did not deal with finding reasons behind satisfaction or dissatisfaction regarding neighbourhood characteristics. The reasons behind using locations with mismatch situation $\mathrm{AbPg}$ (Actual bad Perceived good) can be given based on positive perception of other neighbourhood characteristics. The reason can be that people are satisfied with some other neighbourhood characteristics despite of bad environmental quality. For instance, for city centre, participants had positive perception regarding service availability, cleanliness, and safety.

The comparative study of actual and perceived environmental quality helped in identifying the locations in both areas where the match and mismatch existed. The result showed that deprived area had more locations with match situation, $\mathrm{AbPb}$ (Actual bad Perceived bad) regarding noise in comparison to affluent area. Likewise, more locations were identified with mismatch situation,
$\mathrm{AgPb}$ (Actual good Perceived bad) regarding all three indicators of environmental quality in Nordstadt. However, for mismatch situation $\mathrm{AbPg}$ (Actual bad Perceived good) regarding noise, more locations were identified in Kreuzviertel. The study also indicated that more locations identified as health opportunities were avoided by respondents from Nordstadt because of bad perception of environmental quality. It was also found that respondents from Nordstadt were dissatisfied with the environmental quality of the locations inside their neighbourhood and they avoided health opportunities in such locations.

The result shows that Nordstadt need more attention. To find out more detailed explanations for differences between actual and perceived environmental situation, more in-depth research is needed. This result shows that upon acknowledging the opinion of people can reveal the real situation of their neighbourhood.

\section{Conclusion}

The main findings from this research can be summarised comparatively for two areas; Nordstadt and Kreuzviertel. There were similarities and differences in the results. Participants from both areas mentioned social relationship mostly as healthrelated activity. Walking as physical activity was reported most after meeting friends. Parks came out to be the location mostly used as health opportunities for different health related activities by respondents from both areas. Use of parks was associated with safety more than with air quality and noise level for respondents from Nordstadt. On the contrary, for participants from Kreuzviertel, use of parks was more associated with environmental qualities (air quality and noise) than with safety. The use of parks has shown importance of green areas. The study has also put forward negative and positive perception of neighbourhood characteristics associated with different locations. Such information can be taken as useful insights as planners and decision-makers can further plan development programs based on peoples' need. The research provides an opportunity to formulate policies that address main problems acting as barriers to get benefits from health opportunities. 


\section{Acknowledgement}

I would like to express my sincere gratitude to the scholarship Erasmus Mundus, EMMA-West 2013 offered by European Union for financially supporting to pursue MSc study at ITC, University of Twente. I would also like to thank ITC for providing me this opportunity of studying Urban Management and Geo-Information science.

\section{References}

[1] Barton, H., and Grant, M. (2013). Urban planning for healthy cities. A review of the progress of the European Healthy Cities Programme. Journal of Urban Health : Bulletin of the New York Academy of Medicine, $90 \quad$ Suppl 1(1), 129-41. http://doi.org/10.1007/s11524-011-9649-3

[2] Braveman, P. (2003). Defining equity in health. Journal of Epidemiology and Community Health, 57(4), 254-258. http://doi.org/10.1136/jech.57.4.254

[3] Chappell, N., and Funk, L. (2004). Lay perceptions of neighbourhood health. Health and Social Care in the Community, 12(3), 243-253. http://doi.org/10.1111/ j.1365-2524.2004.00493.x

[4] City History - Home. (n.d.). Retrieved August 23, 2015, from http://www.dortmund.de/de/leben_in _dortmund/stadtportraet/stadtgeschichte/startseite_stg /index.html

[5] Cohen, D. A., Mason, K., Bedimo, A., Scribner, R., Basolo, V., and Farley, T. A. (2003). Neighborhood Physical Conditions and Health. American Journal of Public Health, 93(3), 467-471. http://doi.org/10.2105/AJPH.93.3.467

[6] EEA. (2014). Noise in Europe 2014. Denmark. Retrieved from http://bookshop.europa.eu/en/noisein-europe-2014-pbTHAL14010/?CatalogCategoryI

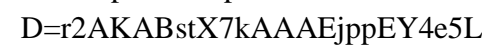

[7] Flacke, J., and Kockler, H. (2015). Spatial urban health equity indicators- a framework-based approach supporting spatial decision making. In O. Ozcevik, C. A. Brebbia, and S. M. Sener (Eds.), Sustainable Development and Planning VII (pp. 365-376). WIT Press.

[8] Giles-Corti, B., and Donovan, R. J. (2002). The relative influence of individual, social and physical environment determinants of physical activity. Social Science and Medicine, 54(12), 1793-1812. http://doi.org/10.1016/S0277-9536(01)00150-2
[9] Kruize, H. (2007). On ennvironmental equity: Exploring the distribution of environmental quality among socio-economic categories in the Netherlands. Copernicus Institute for Sustainable Development and Innovation.

[10] Lee, C., and Moudon, A. (2004). Physical activity and environment research in the health field: implications for urban and transportation planning practice and research. Journal of Planning Literature. Retrieved from http://jpl.sagepub.com/content/ 19/2/147.short

[11] Links - History - Town portrait - life in Dortmund city portal dortmund.de. (n.d.). Retrieved August 23, 2015,from http://www.dortmund.de/de/leben _ in dortmund/stadtportraet/stadtgeschichte/links_stadtges chichte/index.html

[12] Maas, J., van Dillen, S. M. E., Verheij, R. A., and Groenewegen, P. P. (2009). Social contacts as a possible mechanism behind the relation between green space and health. Health and Place, 15(2), 586-95.

[13] Oppenheim, A. N. (1992). Questionnaire Design, Interviewing and Attitude Measurment. Pinter Publishers Ltd.

[14] Parkes, A., Kearns, A., and Atkinson, R. (2002). What Makes People Dissatisfied with their Neighbourhoods? Urban Studies, 39(13), 2413-2438.

[15] Perlstadt, H. (2014). Community Intervention. (J. M. Fritz and J. Rhéaume, Eds.). New York, NY: Springer New York. http://doi.org/10.1007/978-1-4939-0998-8

[16] Roosa, M. W., White, R. M. B., Zeiders, K. H., and Tein, J.-Y. (2009). An Examination of the Role of Perceptions in Neighborhood Research. Journal of Community Psychology, 37(3), 327-341.

[17] SimuPLAN. (2013). Modellgestutzte Ermittlung der Immissionsbeitrage aller relevanten Quellgruppen fur das Stadtgebiet von Dortmund.

[18] WHO. (2011). Burden of disease from environmental noise-Quantification of healthy life years lost in Europe. Denmark. Retrieved from http://www.who.int/quantifying_ehimpacts/publicatio ns/e94888.pdf?ua=1

[19] WHO, and UN Habitat. (2010). Hidden cities: Unmasking and overcoming health inequities in urban settings. Geneva: World Health Organization. Retrieved from http://www.who.int/kobe_centre/ publications/hidden_cities2010/en/ 